\title{
Methodological landscape in research on teacher identity in mathematics education: a review
}

\author{
Sonja Lutovac ${ }^{1}$ (1) $\cdot$ Raimo Kaasila $^{1}$
}

Accepted: 27 October 2018 / Published online: 2 November 2018

(c) The Author(s) 2018

\begin{abstract}
A vast body of research has shown that teacher identity matters, be it in mathematics or in any other subject. The means of investigating teacher identity greatly determine the knowledge we have; however, no review of the methodological approaches into this topic has yet been conducted. This paper provides an overview of the methodological approaches in the research on teacher identity in mathematics education, in order to initiate a discussion on developmental possibilities in terms of how future research on this topic could be carried out. We examine 52 studies, published between 2000 and 2017 in peer-reviewed scholarly journals, investigating the identities of student teachers and/or practitioners who were generalists and/or specialised mathematics teachers. We identified the following to be prevalent data sources in qualitative approaches: interviews, written reflections or narratives, and classroom observations. In terms of analytical approaches, the scene is rather monotonous. Finally, we provide suggestions for future methodological considerations, highlighting the need for researchers to label their methodological decisions in order to better situate and connect their work to other research on mathematics-related teacher identity.
\end{abstract}

Keywords Teacher identity $\cdot$ Mathematics education $\cdot$ Methodology $\cdot$ Qualitative research $\cdot$ Review

\section{Introduction}

Research on identity in mathematics education has grown since 2000 , as recorded by the vast body of research into this topic, including this special issue. Recent review studies have confirmed the popularity of this topic (Darragh 2016; Goldin et al. 2016; Lutovac and Kaasila 2018) and provided suggestions for future studies. For example, Darragh (2016) suggested a greater focus on the performative perspective on identity in mathematics education research, arguing that identity as performance can be accomplished in many ways, stems from the identifying of oneself and/ or others, and, importantly, considers the audience, whose role in the identifying process is inevitable. Goldin et al. (2016) provided a brief overview of the research on students'

Electronic supplementary material The online version of this article (https://doi.org/10.1007/s11858-018-1009-2) contains supplementary material, which is available to authorized users.

Sonja Lutovac

sonja.lutovac@oulu.fi

1 Faculty of Education, University of Oulu, Oulu, Finland and teachers' identities, highlighting the need to examine both simultaneously. Most recently, we examined studies on teacher identity in mathematics education, observing a disconnect between research on identity in mathematics education and that in general education (Lutovac and Kaasila 2018). Mathematics education researchers, arguably, have not taken full advantage of the theoretical frameworks and/ or findings conducted in general education contexts. As a result, a gap between the general and subject-specific education domains, such as mathematics, has been created, hindering the engagement of mathematics education researchers in wider education research discussions (Lutovac and Kaasila 2018). We argued that this disconnect must be minimised to support better knowledge transfer between domains.

These review studies show that identity in mathematics education research is contextualised in various ways. In the context of school mathematics, researchers have shown that learners' identities greatly determine how students learn, and the kinds of relationships they develop with the subject (Black et al. 2009, 2010). Much research has been done in the pre-service teacher education context, exploring the process of becoming a mathematics teacher (Brown and McNamara 2011; Ma and Singer-Gabella 2011; van Putten et al. 
2014). Although less common, some studies in this line have also tackled the identities of teacher educators to provide a better understanding of how teacher educators mediate and influence the process of identity development (e.g., Allen et al. 2016; Heyd-Metzuyanim et al. 2016). The identities of practicing teachers have also been scrutinised, particularly in terms of how they develop over time, how they shape and are shaped by teachers' practices (Andersson 2011; Gujarati 2013; Hobbs 2012a, b; Losano et al. 2018; Oslund 2016), and how they interact with students' evolving identities (Clark et al. 2013; Heyd-Metzuyanim 2013).

In this paper, we are particularly interested in teacher identity in the pre-service, in-service, and higher education contexts. We have elsewhere observed the use of differing terminologies, theoretical perspectives, and definitions in research on teacher identity (Lutovac and Kaasila 2018), demonstrating the overall diversity of lenses guiding researchers' explorations. These lenses include, for example, the socio-cultural perspective (e.g., Bennison 2015; Essien 2014; van Zoest and Bohl 2005), the post-structural perspective (de Freitas 2008; Llewellyn 2009; Walshaw 2013), and a more eclectic theoretical perspective combining several interrelated research areas in and outside of the mathematics education (Kaasila et al. 2008, 2012; Kasten et al. 2014; van Putten et al. 2014). Each theoretical line employs a different definition of teacher identity; however, most researchers define identity in terms of who teachers understand themselves to be in relation to mathematics and its teaching (e.g., Brown and McNamara 2011; Hodgen and Askew 2007; Jones et al. 2000). The terms used in this research domain include 'mathematical identity' (Kaasila et al. 2008; Lutovac and Kaasila 2011, 2014), 'mathematics teacher identity' (van Zoest and Bohl 2005), 'professional mathematics teacher identity' (van Putten et al. 2014) and 'mathematics-related teacher identity' (Lutovac and Kaasila 2018). To discuss the identities of all teachers who teach or will teach mathematics in the future (i.e., not only specialised mathematics teachers, but also non-specialists, such as elementary teachers), we find the term 'mathematics-related teacher identity' particularly useful. Regardless of how the concept of teacher identity is used, it is the topic itself that undoubtedly matters as it helps us to understand teachers' learning and their instructional practices, and how different contexts influence these (Hodges and Hodge 2017).

In our earlier paper (Lutovac and Kaasila 2018), we categorised the findings of this vast body research as providing knowledge on the following: (1) theoretical models and what constitutes teacher identity (Bennison 2015; Boylan and Woolsey 2015; van Zoest and Bohl 2005); (2) contextual factors in teacher identity development (de Freitas 2008; Goos and Bennison 2008; Hobbs 2012a, b; Hodges and Cady 2012; Kasten et al. 2014; Lutovac and Kaasila 2014); (3) identity development in pre- and in-service teacher education (Bjuland et al. 2012; Chronaki and Matos 2014; Hossain et al. 2013; Llewellyn 2009; Lutovac and Kaasila 2011, 2014); (4) affective relationships with mathematics and the process of change in teacher identity (Drake et al. 2001; Hodgen and Askew 2007; Kaasila et al. 2008); (5) power, social justice, gendered discourses, and race in teacher identity development (Boylan and Woolsey 2015; de Freitas 2008; Llewellyn 2009; Walshaw 2013); and (6) the link between identity and teaching practices (Andersson 2011; Clark et al. 2013; Goos 2005; Gujarati 2013; Hobbs 2012b; Ma and Singer-Gabella 2011; van Putten et al. 2014).

Review studies examining exclusively methodological approaches in mathematics education research are rare. The aforementioned reviews of identity research (Darragh 2016; Lutovac and Kaasila 2018) provide only brief and rather general methodological suggestions, and only to complement other topics of discussion. While we know that the methodological approaches to research on teacher identity are usually qualitative and typically use interviews as a data collection method, there is a need for a systematic review of existing research methods. The means of exploring teacher identity greatly determine our knowledge about it; thus, they are worthy of more detailed consideration. A focus on how, as opposed to only what, will help to develop this line of research further.

This paper synthesizes the methodological approaches to research on teacher identity in mathematics education. We examine 52 studies, published between 2000 and 2017 in peer-reviewed scholarly journals, investigating the identities of student teachers and/or practitioners who are generalists and/or specialised mathematics teachers. We contribute to the vast body of work on identity in mathematics education by initiating a discussion of possibilities for methodological developments in future research on this topic. We do not intend to question the methodological choices of the reviewed studies, as their validity has, arguably, been carefully examined through the peer-review process. Instead, we examine the methodologies more closely, in order to lay out the methodological landscape in this line of research and provide a commentary on where the field is at the present moment and in which direction it could evolve. This review was driven with the following research questions in mind: What kinds of methodological approaches have been used in research on mathematics-related teacher identity? How can the current methodological landscape in research on mathematics-related teacher identity help us with future methodological considerations and avenues? 


\section{Methodology}

\subsection{Data collection: selecting the studies to be reviewed}

This review was conducted as a continuation of our quest to learn about the possible directions of future research on mathematics-related teacher identity. We therefore repeated the same procedure for study inclusion and exclusion used in our previous work (Lutovac and Kaasila 2018), though we did extend the time span of the reviewed studies to include publications published between 2000 and 2017. Since the databases we used to identify studies for inclusion had undergone some changes, we had to make minor changes to our search criteria. The studies to be included in this review were obtained through a twophase collection process.

The first phase was conducted in February 2016. The primary database used was Education and Social Sciences and ERIC (ProQuest), later cross-checked with Academic Search Premier (EBSCO) and Scopus. Based on several trials designed to obtain a relevant, but not overly narrow or broad list of studies published in the field, we developed the following criteria: first, the keywords 'identity', 'teacher', and 'mathematics' all had to appear in the identifiers (keywords $=\mathrm{IF})$ and subject headings $($ all $=\mathrm{SU})$, and second, among those we chose the studies that were written in English and published between 2000 and 2015 in peer-reviewed scholarly journals. Thus, conference proceedings, books, and dissertations were excluded. After the cross-check of databases, the elimination of studies that did not fit the criteria, and the elimination of duplicates, this first phase yielded in 40 publications to be examined.

The second phase of the search was conducted in December 2017 and repeated in February 2018. We replicated the steps of the first phase, but considered only studies published from the beginning of 2016 until the end of 2017. In addition, due to changes in the used databases, we could no longer select for keywords to appear in identifiers (keywords $=I F$ ), as this option simply did not exist anymore. Therefore, we searched for the keywords in all subjects and indexing (SU) and in anywhere except full text (ALL). We again cross-checked the results of the three databases. The search in Scopus allowed for the application of the old search criteria [i.e. searching the three keywords in identifiers (IF), such as titles, abstracts, and keywords]. This second phase yielded an additional 12 publications. In all, therefore, we identified 52 publications to be examined carefully in terms of their methodological approaches.

Several criteria led to the exclusion of certain studies. As previously mentioned, we did not consider conference proceedings, books, or dissertations. As a result of the various theoretical perspectives on identity, some researchers use different terms that can be understood as synonyms for identity (e.g., subjectivity) or related terms (e.g., identifying or becoming). Since we were interested specifically in the concept of identity, studies using these alternative terms were excluded. In addition, studies that matched our criteria but did not focus primarily on teacher identity were also excluded. Since we focus on studies exploring teacher identities, we further excluded studies on mathematics coaches or leaders (e.g., Chval et al. 2010; Knapp 2017). Because teacher educators often have extensive teaching and can also be considered teachers, we did take into account the studies of teacher educators' identities in the context of mathematics (e.g., Allen et al. 2016; Essien 2014). Finally, we considered only studies on teacher identity pertaining to the context of mathematics education.

We wish to acknowledge some limitations in our search which resulted in some missed studies. Limited to only three data bases our search generated some inconsistencies in terms of the regional journals included and missed some studies in highly respected journals. In addition, our search functions were limited to identifiers, such as titles and keywords, excluding the abstracts. Had we expanded the number of data bases and included the abstracts as a search function, we would have obtained a more comprehensive body of studies to be reviewed. We thus acknowledge that this literature review is not exhaustive, but it does provide a solid overall picture of the methodologies used in teacher identity research in mathematics education contexts, and it also provides an insight into a sufficiently broad spectrum of the researchers that investigate the topic of identity.

\subsection{Meta-ethnography as analytical approach}

We apply here the principles of meta-ethnography, a method for interpretive synthesis (Noblit and Hare 1988; see also; Britten et al. 2002). The method has been used for smallscale review studies of qualitative research, which fits well the amount and the type of studies we review here (see also, Fink 2013). This approach allows us, firstly, to present an overall view of the kind of study designs, data collection methods and analytical techniques that were used in the reviewed studies, and secondly, it assists us in providing our interpretive commentary on the issues we deem worthy of further consideration. In what follows, we describe the steps we took to analyze the chosen studies.

The first phase of the analysis was aggregative. We were guided by questions such as the following: what was the overall study design (e.g., case study, phenomenological study, etc.), who were the participants, how many participants were there, how were the participants selected, what kind of data collection methods were used, how long did the 
data collection last, and which methods of data analysis were applied and in what way? We therefore first read all the studies in a holistic manner, marking all the passages containing "methodological" information. Several articles explain their methodological decisions in other sections of their papers, which we took into account, however, the central data set for the analysis were methodological sections of the selected 52 articles, as these are usually communicating to the readers most information about the ways the studies were carried out. This reading gave us some preliminary answers to our questions, but most importantly, it led to data extraction for further work (Britten et al. 2002; Dixon-Woods et al. 2005). As we did not want to lose any important methodological detail, and researchers' own perspectives on their methodologies, we used verbatim extraction, which was later simplified and shortened. The result of this process is Table 4 (see Online Appendix). Additionally, we each wrote our own notes for each study, and made a collective summary of all the observations. We wanted to synthesize the findings in line with the commonly used themes in methodological sections of research articles, which led to the decision to construct the additional tables we present in our findings (see Tables 1, 2, 3).

Then we proceeded with the second, interpretive phase of the analysis, the result of which was the commentary we provide in the discussion. In line with the interpretive stance, the themes of the commentary were not specified beforehand (Dixon-Woods et al. 2005). We read the studies independently, but later jointly reviewed our notes and summaries. For the most part, there was high agreement in our observations. The themes for our commentary were chosen based on the synthesis generated in the first analytical phase and commonalities in each of our collective summaries. We also acknowledge that our own 'insider' viewpoint in the mathematics-related teacher identity research played a role in the choice of these themes.

\section{Overview of the methodological approaches in research on mathematics-related teacher identity}

In our examination, we first classified the reviewed articles according to the type of publication. Most of the examined studies were empirical; however, two were theoretical (Bennison 2015; van Zoest and Bohl 2005), one was a review paper (Lutovac and Kaasila 2018), and one was practitioneroriented (Leatham and Hill 2010). Secondly, we classified all 48 empirical studies according to their methodological approach and study design (see Table 1). We note here that the examples of the studies in the in-text citations are selected and therefore, not exhaustive.

Table 1 shows that all the 48 empirical studies applied a qualitative approach, with only one explicitly labelled as mixed-methods (Woolhouse and Cochrane 2015). We further categorised the study designs as follows: (1) case study, (2) narrative study, (3) phenomenological study, (4) ethnographic study, (5) mixed-methods study, (7) video study, (8) self-study, and (9) qualitative approach with no explicitly mentioned design, as shown in Table 1 . Table 1 was constructed in a data-driven manner; therefore, the design categories originate from the reviewed studies and the authors' own labels. Some studies used more complex or compound study designs; these were categorised based on the dominant approach. For example, the study by Jong (2016) was labelled by the author as a phenomenological case study, and

Table 1 Methodological approaches and study designs of the examined empirical studies

\begin{tabular}{|c|c|c|}
\hline Study design & $\begin{array}{l}\text { Number } \\
\text { of studies }\end{array}$ & Studies \\
\hline Case study & 9 & $\begin{array}{l}\text { Andersson (2011); de Freitas (2008); Goos (2005); Gujarati (2013); Heyd-Metzuyanim et al.i } \\
\text { (2016); Jong (2016); Losano et al. (2018); Spillane (2000); van Putten et al. (2014) }\end{array}$ \\
\hline Narrative study & 10 & $\begin{array}{l}\text { Bjuland et al. (2012); Drake et al. (2001); Hodges and Hodge (2017); Kaasila et al. (2012); } \\
\text { Kaasila et al. (2008); Lutovac and Kaasila (2011, 2014); McCulloch et al. (2013); Oslund } \\
\text { (2016); Wassell (2006) }\end{array}$ \\
\hline Phenomenological study & 2 & Nichols et al. (2017); Pipere and Mičule (2014) \\
\hline Ethnographic study & 2 & Chronaki and Matos (2014); Palmér (2016) \\
\hline Video study & 1 & Hobbs (2012b) \\
\hline Self-study & 1 & Allen et al. (2016) \\
\hline Mixed-methods study & 1 & Woolhouse and Cochrane (2015) \\
\hline $\begin{array}{l}\text { Qualitative approach (no explicit } \\
\text { naming or mention of the } \\
\text { design) }\end{array}$ & 22 & $\begin{array}{l}\text { Alderton (2017); Boylan and Woolsey (2015); Chen (2017); Clark et al. (2013); Essien (2014); } \\
\text { Goos and Bennison (2008); Hobbs (2012a); Hodgen and Askew (2007); Hossain et al. (2013); } \\
\text { Hodges and Cady (2012); Kasten et al. (2014); Llewellyn (2009) } \\
\text { Ma and Singer-Gabella (2011); Mosvold and Bjuland (2016); Neumayer-Depiper (2013); Owens } \\
\text { (2008, 2014); Pausigere and Graven (2013); Skog and Andersson (2015); Spitler (2012); } \\
\text { Walshaw (2013); Williams (2011) }\end{array}$ \\
\hline
\end{tabular}


Table 2 Data collection methods in the examined studies

\begin{tabular}{lc}
\hline Data collection method & $\begin{array}{l}\text { Number } \\
\text { of studies }\end{array}$ \\
\hline Interviews and focus groups & 35 \\
Individual & 34 \\
Not specified & 15 \\
Semi-structured & 14 \\
Other (e.g., open ended, reflective, in-depth, informal) & 10 \\
(Focus) group interviews & 7 \\
Other interaction-based data & 9 \\
Email correspondence and letters & 3 \\
(Informal) discussions/meetings/presentations & 4 \\
Debriefing conversations & 1 \\
Web-based discussion & 1 \\
Observations and ethnographic data & 20 \\
Non-participatory & 13 \\
Participatory & 3 \\
Field notes & 6 \\
Research journals & 2 \\
Self-recordings & 2 \\
Written data and other artefacts & 1 \\
Written reflections/narratives and autobiographies & 8 \\
Student reports and other assignments ${ }^{\mathrm{a}}$ & 6 \\
Drawings & 1 \\
Student feedback & \\
Course documents & 2 \\
Policy documents & 1 \\
Artifacts not specified & 6 \\
Video-recordings & 6 \\
Surveys and questionnaires & 1 \\
\hline & 2 \\
\hline
\end{tabular}

The numbers in Table 2 do not add up as various types of data (e.g., various interviews) were collected within a single study

aThe word "student" here does not refer to student teachers, but the students who were taught by either pre- or in-service teachers

we have categorised it as a case study. The authors of the studies in the last category-qualitative approach with no explicitly mentioned design—-did not provide explicit information about their study designs, and often did not even explicitly state that their studies were qualitative; however, the latter was evident from the findings and further discussion. Table 1 shows that almost a half of the reviewed studies did not mention a specific study design. Of those that did, narrative (10) and case (9) studies accounted for over twothirds of study designs.

Most of the reviewed studies on mathematics-related teacher identity were small in scale (see Online Appendix): 21 reported 1-2 participants (e.g., Andersson 2011; Bjuland et al. 2012; Williams 2011), 17 reported 3-10 participants (e.g., Gujarati 2013; Hobbs 2012b; Nichols et al. 2017; Pipere and Mičule 2014), and 9 reported more than 10 participants (e.g., Kasten et al. 2014; Owens 2014; Woolhouse and Cochrane 2015). Even researchers examining larger numbers of participants chose to centre their findings and discussions on fewer cases. The research participants in the examined studies were pre-service teachers and/or in-service teachers who were generalists and/or specialised mathematics teachers. Of the reviewed studies, 22 addressed pre-service teachers' identities (e.g., Alderton 2017; Hodges and Hodge 2017), 22 addressed in-service teachers' identities (e.g., Losano et al. 2018; Nichols et al. 2017), 1 examined the pre- and in-service training phase (Owens 2014), and 3 addressed teacher educators' identities (Allen et al. 2016; Essien 2014; Heyd-Metzuyanim et al. 2016). The rest of the studies, by the nature of their design, did not directly involve any participants. It also became apparent that the specialist and non-specialist mathematics teachers have for the most part been studied in isolation from each other (see Online Table 4).

Most studies collected data over a period of 1 year or more (e.g., Goos and Bennison 2008; Hodgen and Askew 2007; Palmér 2016), and only a few studies relied on data collected at a single time point (e.g., Lutovac and Kaasila 2011, 2014; Nichols et al. 2017). As Online Table 4 shows, some studies included an exceptional amount of data collected via several versatile methods (Bjuland et al. 2012; Gujarati 2013; Hodgen and Askew 2007; Hodges and Hodge 2017; Jong 2016; Palmér 2016; Wassell 2006). While the raw data included audio, video, and textual data, the analyses of the non-textual data were based on text transcriptions. Table 2 presents a more detailed picture of the data collection methods.

The most common methods of data collection were various formats of interviews, and written data and other artefacts. Two-thirds of the examined studies involved interviews with individuals (e.g., Llewellyn 2009; Skog and Andersson 2015; Wassell 2006). Various formats of interviews, such as semi-structured, open-ended, reflective, etc. were found also within a single study (Hobbs 2012b; Hodgen and Askew 2007; Wassell 2006). Although researchers often did not specify the type of the interview, semi-structured appear to prevail. In 7 studies, group interviews or focus groups were conducted (e.g., Palmér 2016; Wassell 2006; Woolhouse and Cochrane 2015). In 21 studies, some type of written data and artefacts were collected, including written reflections and autobiographies (de Freitas 2008; Hodges and Hodge 2017; McCulloch et al. 2013), or various student assignments (Hodges and Cady 2012; Ma and Singer-Gabella 2011; Wassell 2006).

We identified also the use of observations and of ethnographic data. While non-participatory classroom observation was applied in over a half of these studies (Goos 2005; Jong 2016; Owens 2008; Williams 2011), only the two ethnographic studies (Chronaki and Matos 2014; Palmér 2016) and one narrative study (Wassell 2006) used participatory 
Table 3 Data analysis methods in the examined studies

\begin{tabular}{|c|c|c|}
\hline Data analysis method as named in the examined studies & $\begin{array}{l}\text { Number } \\
\text { of stud- } \\
\text { ies }\end{array}$ & Examples of studies \\
\hline $\begin{array}{l}\text { Grounded theory, open coding and data-driven (thematic) } \\
\text { analysis }\end{array}$ & 11 & $\begin{array}{l}\text { Chen (2017); Gujarati (2013); Hobbs (2012a); Jong (2016); } \\
\text { Kasten et al. (2014); Nichols et al. (2017), Palmér (2016), Pipere } \\
\text { and Mičule (2014); Spillane (2000); van Putten et al. (2014); } \\
\text { Woolhouse and Cochrane (2015) }\end{array}$ \\
\hline Narrative and performative narrative analysis & 11 & $\begin{array}{l}\text { Andersson (2011); Drake et al. (2001); Hodges and Hodge (2017); } \\
\text { Kaasila et al. (2012); Kaasila et al. (2008); Losano et al. (2018); } \\
\text { Lutovac and Kaasila (2011, 2014); McCulloch et al. (2013); } \\
\text { Oslund (2016); Wassell (2006) }\end{array}$ \\
\hline Discourse and/or positioning analysis & 11 & $\begin{array}{l}\text { Boylan and Woolsey (2015); Chronaki and Matos (2014); de Frei- } \\
\text { tas (2008); Hossain et al. (2013); Kaasila et al. (2012); Llewellyn } \\
\text { (2009); Ma and Singer-Gabella (2011); Mosvold and Bjuland } \\
\text { (2016); Neumayer-Depiper (2013); Skog and Andersson (2015); } \\
\text { Walshaw (2013) }\end{array}$ \\
\hline Communicational, linguistic and/or rhetoric analysis & 2 & Heyd-Metzuyanim et al. (2016); Kaasila et al. (2012) \\
\hline Framework-driven thematic/content analysis & 15 & $\begin{array}{l}\text { Alderton (2017); Allen et al. (2016); Andersson (2011); Bju- } \\
\text { land et al. (2012); Boylan and Woolsey (2015); Chen (2017); } \\
\text { Essien (2014); Goos (2005); Goos and Bennison (2008); Hobbs } \\
\text { (2012b); Hodgen and Askew (2007); Hodges and Cady (2012); } \\
\text { Mosvold and Bjuland (2016); Pausigere and Graven (2013); } \\
\text { Williams (2011) }\end{array}$ \\
\hline Document content analysis & 2 & Owens (2014); Pausigere and Graven (2013) \\
\hline Statistical analysis & 1 & Woolhouse and Cochrane (2015) \\
\hline
\end{tabular}

observations. One study examined official policy documents (Pausingere and Graven 2013), 9 some type of interactionbased data (Alderton 2017; Andersson 2011; Goos and Bennison 2008; Gujarati 2013), and 6 studies video-recordings (Heyd-Metzuyanim et al. 2016; Mosvold and Bjuland 2016; Essien 2014). Surveys and questionnaires (e.g. Goos 2005; van Putten et al. 2014; Woolhouse and Cochrane 2015), and videos (e.g., Drake et al. 2001; Essien 2014; Hobbs 2012b; Ma and Singer-Gabella 2011; Wassell 2006) combined, were used in a little over one-third of empirical studies.

We further examined all studies in terms of their data analysis methods. In Table 3, we summarise these methods. The studies were first grouped according to the labels the researchers used to name and/or explain their analyses, which we have synthesized under one or more of the following categories: (1) grounded theory, open coding and datadriven (thematic) analysis, (2) narrative and performative narrative analysis, (3) discourse and/or positioning analysis, (4) communicational, linguistic and/or rhetoric analysis, (5) framework-driven thematic/content analysis, (6) document content analysis, and (7) statistical analysis. These categories were created in a data-driven manner; based on the researchers' labels of their analyses, we synthesized analytical techniques in those categories. It is important to note that although researchers described their methods of analyses, they often did not name them, which posed challenges for our categorization. We discuss those in our commentary.
Table 3 shows that performance based approach to analysis, as suggested by Darragh (2016), was applied in half of the reviewed studies belonging to the categories 'narrative and performative narrative analysis', 'discourse and/or positioning analysis and communicational', and 'linguistic and/or rhetoric analysis'. Overall, the use of pre-determined thematic categories to analyse the data or framework-driven analyses was found in over a third of the reviewed studies. While these studies explicitly speak of theory driven analysis, we identified such analysis also within other categories. We build on this finding in our commentary. Authors drew heavily on discourse theory, Wenger's (1998) community of practice (Essien 2014; Goos and Bennison 2008; Hodgen and Askew 2007), Holland et al.'s (1998) figured worlds (Ma and SingerGabella 2011; Williams 2011), Valsiner's (1997) theory of three-zone development (Goos 2005), and Sfard and Prusak's (2005) narrative identity framework (Andersson 2011; Bjuland et al. 2012; Mosvold and Bjuland 2016). Data-driven analyses, however, were surprisingly scarce, and only a few studies underlined their data-driven nature explicitly (e.g., Pipere and Mičule 2014; Gujarati 2013). A few studies applied more than one method of analysis (e.g., Hodgen and Askew 2007; Hodges and Cady 2012; Kaasila et al. 2012). 


\section{Discussion}

This review provided an overall picture of the methodological landscape in the current research on mathematicsrelated teacher identity, based on 52 peer-reviewed journal papers published between 2000 and 2017. During the holistic reading of the papers and synthesis of the research via several tables (see Tables 1, 2, 3; Online Table 4), our personal observations regarding methodological information provided in these papers arose. These observations are tightly bound, but not limited, to the challenges we encountered in synthesizing the studies in question. As noted by Sandelowski et al. (1997), synthesizing existing research methodologies is important for various reasons, such as for advancing the analytic procedures, enhancing the generalizability of qualitative research, and illuminating key methodological problems that need to be solved. We here mention the challenges we encountered in this review as an outset for future methodological considerations.

While the participant selection criteria and the participants themselves were generally well described, in constructing Online Table 4, we occasionally encountered a difficulty in understanding who the participants were. Were they generalists or specialists and, for example, at which level of education pre-service teachers were planning to teach once they completed their studies (see also Lutovac and Kaasila 2018)? Thus, identifying who the participants under investigation were, was not a straightforward process and it occasionally required 'decoding' on our part. What seems to complicate this matter is the versatile vocabulary we as researchers use to describe these decisions. With respect to the participants and as evident in Online Table 4, researchers strictly position themselves in one educational context, leading to the examination of only generalist or specialist pre- or in-service teachers (Lutovac and Kaasila 2018). Methodological decisions that will allow for simultaneous data collection based on both cohort samples could be a valid methodological avenue in future research on teacher identity in the mathematics education context. Placing these subjects side by side would also allow greater transfer of knowledge and improvement of mathematics teacher education of both groups.

Further, in terms of data collection, we observed that procedures were usually well described and clear, and many studies used multiple and versatile methods of data collection. We compared our findings with the methodological questions Izadinia (2013) raised in her review of research on student teachers' professional identity in the general educational context. Interestingly, our findings differed in the following ways. For example, the majority of the studies we reviewed collected data over 2 years or more (e.g., Bjuland et al. 2012; Goos and Bennison 2008; Hodgen and Askew 2007; Jong 2016; Palmér 2016; Spillane 2000), rather than within a shorter time span (e.g., from a few months to a year). The benefit of a longer time span is obvious, as the authors could provide a better account of teachers' changes (e.g., Bjuland et al. 2012; Hodgen and Askew 2007; Kaasila et al. 2012) or could analyse, for example, the transition from teacher training to actual practice (e.g., Hodges and Hodge 2017). Our findings also clearly differ in that class observations appear to be common in mathematics-related teacher identity research. As shown in the Table 2, 13 reviewed studies included class observations (e.g., Goos 2005; Hobbs 2012b; Hodgen and Askew 2007; Jong 2016; Owens 2008; Spillane 2000; Williams 2011), and 3 included even participatory class observations (Chronaki and Matos 2014; Palmér 2016; Wassell 2006). Class observation data add value by addressing not only whether teachers really teach in line with who they are, as suggested by Hamachek (1999), but also how the various factors of practice shape teachers' identities. Similar to the findings in general educational contexts, the use of reflection and various reflective activities to 'access' teacher identity is also common in mathematics education research. This is not surprising, as, for example, Giddens (1991) labelled identity as a reflexive project of the self, and it is commonly acknowledged that identity construction is a reflective work (Beauchamp and Thomas 2009; Rodgers and Scott 2008). If identity itself is a reflective construct, it makes sense to investigate it by encouraging teachers' reflective processes and allowing their identities to surface and develop simultaneously.

We also observed that all the studies were qualitative in nature (see Table 1) using a variety of applications of the same study design or a variety of variations of a particular analytic technique (e.g., narrative). Moreover, there is a variety of labels attached to these methodological decisions. However, what was surprising is that almost half of the studies take the qualitative approach to the study of identity for granted, leaving it for the reader alone to come to the understanding that he/she is reading a piece of qualitative research. We observed a similar picture with respect to methods of analysis, which were often left without any label. The absence of such labels complicated the production of this synthesis and the methodological comparability of the studies in question (Sandelowski et al. 1997; see also; Fink 2013). We do not imply that the labels are what matters most, rather, we hold that the labels are a necessary addition to the clear description of what has been done and an explanation of why it has been done that way. Akin to keywords and other commonly used ways to categorize and situate our research among the body of other work, we argue that the 
field would benefit from mathematics education researchers stating their methodological decisions too. This practice would provide a structure to what appears to be a messy field and allow for better comparability of the methods in this line of research.

Another observation regarding analytical techniques is what we refer to here as a taken-for-granted methodological authority (see e.g., Wellman 1994), displayed in two-fold manner. Firstly, authors assumed that the readers know how the data were analysed when referring to seminal work and, therefore, provided no further information. These authors relied on the authority of the acknowledged work, feeling no further need to clarify or justify their decisions or actions. Secondly, the analyses were sometimes entirely unsupported by other important works. These data analysis sections did not include any references, suggesting that the authors felt they had been granted — and, thus, did not need to establish-methodological authority. Clear descriptions of processes, including sufficient support via references, could solve this issue. Additionally, two ways of 'handling' analysis and reporting were identified. While most studies presented their findings in a report-like manner, others included part of the analysis in the findings section. The latter approach usually led to a weaker methodology section. We believe authors may have implemented this structure to avoid redundancy in their writing; however, every study would benefit from a clear, stand-alone methodology section. Regardless of how well the findings display the analysis, a well-explicated and information-rich methodology section cannot and should not be substituted for. It is important to bear in mind that rigor in qualitative research continues to be scrutinised and criticised. Unfortunately, by providing only partial descriptions of our methodological choices and analyses, we continue the cycle of criticism regarding the subjectivity, bias, reproducibility, and generalisability of our qualitative studies.

Noteworthy observation based on the reviewed studies is an imbalance in quantity of papers relying on either data-driven or theory-driven approach. The vast majority of studies, excluding those that explicitly mentioned being data-driven (e.g. Gujarati 2013; van Putten et al. 2014), appeared to rely heavily on frameworks to determine their analyses. Many studies appeared to use data to support or prove theory, rather than develop it. We are aware that, to some extent, all research is framework-driven or interpreted in the light of chosen theories and constructs. We are also aware that analysing the data in a way that is tightly bound to the overarching conceptual framework adds to the validity of the research (Kelle and Buchholtz 2015). However, what we criticise here is the use of these approaches in the very early stages of research. Generally, we adhere to reading of the data with an open-minded lens to form 'local grounded theories' and to connect the findings to the frameworks and 'formal' theories later in the process (Glaser and Strauss 1971 , p. 181). Such a data-driven approach may yield more surprising results and further advance the frameworks used. Akin to previously discussed labeling, this will help in avoiding the disconnect of our work from other works.

Our findings demonstrated that much of the extant research on mathematics-related teacher identity has applied a narrative approach (see Table 1). As we have conducted extensive work on the use of narrative as a theoretical and methodological framework, we were surprised to find that researchers often use the term 'narrative' loosely, without any detailed explanation or definition of exactly what the term means in the concrete analysis of the data. The aforementioned issue of methodological authority is evident here, as well. Researchers tended to simply refer to important studies, thereby requiring readers to be familiar with those studies' particular analyses. In our view, a careful description of analyses, including explicit labelling or naming, followed by support from other relevant work, is much needed here. In addition, the authors of some studies applied a variation of a narrative method that could easily have been labelled thematic analysis, an approach that led us to wonder about this one-sided understanding of the method. Analysing data in terms of narratives is much more than thematic analysis, and disregarding this notion does not allow for the full use of what the approach has to offer. For example, the narrative, which stems from such classic theoretical works as Bruner's (1986) Actual minds, possible worlds and methodological literature such as the works of Polkinghorne (1995) and Lieblich et al. (1998), offers the particular strength of providing a holistic view of the experience and emphasising its uniqueness, rather than fragmenting it into (pre-determined) categories.

One essential aspect of any narrative is emplotment; hence, one important outcome of applying a narrative method is an emplotted story, in which "events and happenings are configured into a temporal unity by means of a plot" (Polkinghorne 1995, p. 6) to account for one's identity (Ricoeur 1991). This, arguably, is the narrative's true value. What we observed, however, was that even when researchers constructed stories based on the collected data, the process of constructing the story's plot was rarely mentioned and/ or sufficiently explicated. It has been argued elsewhere that stories should be taken seriously for what they are and what they can offer to mathematics education researchers, particularly in the investigation of identity (e.g., Sfard and Prusak 2005); however, the current state of the use of narrative left us feeling that the narrative has become a catch-all methodological approach. This may, in the long run, diminish the value of this important method.

Regarding our own methodological decisions, we were reluctant to pinpoint the methodological weaknesses in each individual paper and uneasy about then selecting specific 
authors as examples of what we consider as good practice. We have, therefore, chosen to provide our insights from the reading of the studies in a collective manner. This leaves room for readers to determine how well our observations reflect what has been done on a study-to-study basis (Gough et al. 2012). We do, however, believe that many researchers in this domain will agree with our observations on the intuitive level. While we avoided researcher bias through our search strategies and criteria for inclusion and exclusion of the studies, as well as in our aggregative synthesis, we believe that a certain degree of researcher bias regarding the interpretations here is unavoidable. After all, the synthesis of this body of work was a qualitative, interpretive process, and bound to researchers' perspective. One of the issues we discussed here, for example, was the relevance of labelling methodological approaches, particularly in terms of data analysis. We highlight that this suggestion came about based on the difficulties we encountered while reading and synthesizing the studies. In doing so, it was proven challenging to provide explicit evidence for what is missing in the reviewed studies, the evidence for 'what is not'. We therefore took interpretative authority for the claims we made here (Josselson 2009) and presented our interpretations of the readings with a reflexive and critical lens towards our own conclusions.

In conclusion, future research on mathematics-related teacher identity could benefit from the following methodological recommendations. First, though qualitative approaches are prevalent, it would be interesting to see whether approaches combining quantitative and qualitative methods could be used more productively in studies of identity. Mixed methods studies could support a more versatile view of the phenomenon, as well as a greater generalisation of findings (Kelle and Buchholtz 2015). Second, most of the reviewed studies examined the identities of single groups of pre- or in- service teachers. We suggest gathering data from different teachers of mathematics, such as elementary and mathematics teachers, within a single study. This approach could facilitate an examination of the intersections of identities of teachers who teach mathematics at different levels of education. Moreover, in some recent studies, the selfstudy approach has offered fruitful insights. Combined with other approaches, this method could address, for example, identity development in teacher training from the perspective of future teachers and teacher educators within a single study. Third, multiple sources of data produce fruitful findings and could be further used and developed. Triangulating data, as was done in many of the reviewed studies, ensures the validity of the research. Finally, in the beginning of this quest, we hoped to identify innovative analytical approaches in the research on mathematics-related teacher identity. We believed that such an endeavour would not only help identify new ways of analysing data, but also further develop the field of research. However, the reading of the reviewed studies revealed not only an absence of innovative analytical approaches, but a general weakness in this aspect of the methodology sections of many of the reviewed studies. Researchers should, therefore, discuss their analysis methods more precisely, including labelling of the approaches they use. In order to expand the analytical scene of mathematics education research; we suggest looking outside of our context into general education or more general (e.g. social sciences) research to find other viable analysis methods.

In all, although this review is not comprehensive, it offers important insights into common methods of data collection and analysis in the increasingly explored topic of mathematics-related teacher identity. As such, it seeks to help others in the community and ourselves to dwell further in this topic and set the stage for further reflection upon our means of investigation and the ways in which we present them to others within this research community.

Acknowledgements Open access funding provided by University of Oulu including Oulu University Hospital.

Open Access This article is distributed under the terms of the Creative Commons Attribution 4.0 International License (http://creativeco mmons.org/licenses/by/4.0/), which permits unrestricted use, distribution, and reproduction in any medium, provided you give appropriate credit to the original author(s) and the source, provide a link to the Creative Commons license, and indicate if changes were made.

\section{References}

Alderton, J. (2017). Kelly's story: transformative identity work in primary mathematics teacher education. Gender and Education. https://doi.org/10.1080/09540253.2017.1336204.

Allen, J., Park Rogers, M., \& Borowski, R. (2016). "I am out of my comfort zone": Self-study of the struggle of adapting to the professional identity of a teacher educator. Studying Teacher Education, 12(3), 320-332.

Andersson, A. (2011). A "curling teacher" in mathematics education: Teacher identities and pedagogy development. Mathematics Education Research Journal, 23(4), 437-454.

Beauchamp, C., \& Thomas, L. (2009). Understanding teacher identity: An overview of issues in the literature and implications for teacher education. Cambridge Journal of Education, 39(2), 175-189.

Bennison, A. (2015). Developing an analytic lens for investigating identity as an embedder-of numeracy. Mathematics Education Research Journal, 27(1), 1-19.

Bjuland, R., Cestari, M. L., \& Borgersen, H. E. (2012). Professional mathematics teacher identity: Analysis of reflective narratives from discourses and activities. Journal of Mathematics Teacher Education, 15(5), 405-424.

Black, L., Mendick, H., \& Solomon, Y. (Eds.). (2009). Mathematical relationships in education: Identities and participation. New York: Routledge.

Black, L., Williams, J., Hernandez-Martinez, P., Davis, P., Pampaka, M., \& Wake, G. (2010). Developing a "leading identity": the relationship between students' mathematical identities and their 
career and higher education aspirations. Educational Studies in Mathematics, 73(1), 55-72.

Boylan, M., \& Woolsey, I. (2015). Teacher education for social justice: Mapping identity spaces. Teaching and Teacher Education, 46, 62-71.

Britten, N., Campbell, R., Pope, C., Donovan, J., Morgan, M., \& Pill, R. (2002). Using meta-ethnography to synthesise qualitative research: A worked example. Journal of Health Services and Research Policy, 7, 209-215.

Brown, T., \& McNamara, O. (2011). Becoming a mathematics teacher: Identity and identifications. Dordrecht: Springer.

Chen, R.-J. (2017). Prospective elementary teachers' aesthetic experience and relationships to mathematics. Journal of Mathematics Teacher Education, 20(3), 207-230.

Chronaki, A., \& Matos, A. (2014). Technology use and mathematics teaching: Teacher change as discursive identity work. Learning, Media, and Technology, 39(1), 107-125.

Chval, K. B., Arbaugh, F., Lannin, J. K., van Garderen, D., Cummings, L., Estapa, A. T., \& Huey, M. E. (2010). The transition from experienced teacher to mathematics coach: Establishing a new identity. Elementary School Journal, 111(1), 191-216.

Clark, L. M., Badertscher, E. M., \& Napp, C. (2013). African American mathematics teachers as agents in their African American students' mathematics identity formation. Teachers College Record, $115(2), 1-36$.

Darragh, L. (2016). Identity research in mathematics education. Educational Studies in Mathematics, 93, 19-33.

de Freitas, E. (2008). Troubling teacher identity: Preparing mathematics teachers to teach for diversity. Teaching Education, 19(1), $43-55$.

Dixon-Woods, M., Agarwal, S., Jones, D., Young, B., \& Sutton, A. (2005). Synthesising qualitative and quantitative evidence: A review of possible methods. Journal of Health Services Research and Policy, 10, 45-53.

Drake, C., Spillane, J. P., \& Hufferd-Ackles, K. (2001). Storied identities: Teacher learning and subject-matter context. Journal of Curriculum Studies, 33(1), 1-23.

Essien, A. A. (2014). Examining opportunities for the development of interacting identities within pre-Service teacher education mathematics classrooms. Perspectives in Education, 32(3), 62-77.

Fink, A. (2013). Conducting research literature review: From the internet to paper (4th edn.). Thousand Oaks: Sage.

Giddens, A. (1991). Modernity and Self Identity: self and society in the late modern age. Cambridge: Polity Press.

Glaser, B. G., \& Strauss, A. L. (1971). Status passage. Chicago: Aldine Atherton Inc.

Goldin, G. A., Hannula, M. S., Heyd-Metzuyanim, E., Jansen, A., Kaasila, R., Lutovac, S., ... Zhang, Q. (2016). Attitudes, beliefs, motivation and identity in mathematics education: An overview of the field and future directions. Switzerland: Springer.

Goos, M. (2005). A sociocultural analysis of the development of preservice and beginning teachers' pedagogical identities as users of technology. Journal of Mathematics Teacher Education, 8(1), $35-59$.

Goos, M. E., \& Bennison, A. (2008). Developing a communal identity as beginning teachers of mathematics: Emergence of an online community of practice. Journal of Mathematics Teacher Education, 11(1), 41-60.

Gough, D., Oliver, S., \& Thomas, J. (2012). An introduction to systematic reviews. London: SAGE Publications.

Gujarati, J. (2013). An "inverse" relationship between mathematics identities and classroom practices among early career elementary teachers: The impact of accountability. The Journal of Mathematical Behavior, 32(3), 633-648.

Hamachek, D. (1999). Effective teachers: What they do, how they do it, and the importance of self-knowledge. In R. P. Lipka \& T.
M. Brinthaupt (Eds.), The role of self in teacher development (pp. 189-224). Albany: State University of New York Press.

Heyd-Metzuyanim, E. (2013). The co-construction of learning difficulties in mathematics teacher-student interactions and their role in the development of a disabled mathematical identity. Educational Studies in Mathematics, 83(3), 341-368.

Heyd-Metzuyanim, E., Tabach, M., \& Nachlieli, T. (2016). Opportunities for learning given to prospective mathematics teachers: Between ritual and explorative instruction. Journal of Mathematics Teacher Education, 19, 547-574.

Hobbs, L. (2012a). Teaching "out-of-field" as a boundary-crossing event: Factors shaping teacher identity. International Journal of Science and Mathematics Education, 11(2), 271-297.

Hobbs, L. (2012b). Examining the aesthetic dimensions of teaching: Relationships between teacher knowledge, identity, and passion. Teaching and Teacher Education, 28(5), 718-727.

Hodgen, J., \& Askew, M. (2007). Emotion, identity, and teacher learning: Becoming a primary mathematics teacher. Oxford Review of Education, 33(4), 469-487.

Hodges, T., \& Hodge, L. (2017). Unpacking personal identities for teaching mathematics within the context of prospective teacher education. Journal of Mathematics Teacher Education, 20(2), 101-118.

Hodges, T. E., \& Cady, J. A. (2012). Negotiating contexts to construct an identity as a mathematics teacher. Journal of Educational Research, 105(2), 112-122.

Hossain, S., Mendick, H., \& Adler, J. (2013). Troubling "understanding mathematics indepth": Its role in the identity work of student-teachers in England. Educational Studies in Mathematics, 84(1), 35-48.

Izadinia, M. (2013). A review of research on student teachers' professional identity. British Educational Research Journal, 39(4), 694-713.

Jones, L., Brown, T., Hanley, U., \& McNamara, O. (2000). An enquiry into transitions: From being a 'learner of mathematics' to becoming a 'teacher of mathematics'. Research in Education, 63, 1-10.

Jong, C. (2016). Linking reform-oriented experiences to teacher identity: The case of an elementary mathematics teacher. The Journal of Educational Research, 109(3), 296-310.

Josselson, R. (2009). The present of the past: Dialogues with memory over time. Journal of Personality, 77(3), 647-668.

Kaasila, R., Hannula, M., Laine, A., \& Pehkonen, E. (2008). Socioemotional orientations and teacher change. Educational Studies in Mathematics, 67(2), 111-123.

Kaasila, R., Hannula, M. S., \& Laine, A. (2012). "My personal relationship towards mathematics has necessarily not changed but... Analyzing pre-service teachers' mathematical identity talk. International Journal of Science and Mathematics Education, 10(4), 975-995.

Kasten, S. E., Austin, C., \& Jackson, C. (2014). Am I a mathematics teacher who teaches middle grades or a middle grades teacher who teaches mathematics? Untangling the multiple identities of preservice teachers. Middle Grades Research Journal, 9(2), 127-140.

Kelle, U., \& Buchholtz, N. (2015). The combination of qualitative and quantitative research methods in mathematics education: A "mixed methods" study on the development of the professional knowledge of teachers. In A. Bikner-Ahsbahs, C. Knipping \& N. Presmeg (Eds.), Approaches to qualitative research in mathematics education (pp. 321-361). Dordrecht: Springer.

Knapp, M. C. (2017). An autoethnography of a (reluctant) teacher leader. Journal of Mathematical Behaviour, 46, 251-266.

Leatham, K. R., \& Hill, D. S. (2010). Exploring our complex math identities. Mathematics Teaching in the Middle School, 16(4), 224-231. 
Llewellyn, A. (2009). "Gender games": A post-structural exploration of the prospective teacher, mathematics, and identity. Journal of Mathematics Teacher Education, 12(6), 411-426.

Losano, L., Fiorentini, D., \& Villarreal, M. (2018). The development of a mathematics teacher's professional identity during her first year teaching. Journal of Mathematics Teacher Education, 21(3), 287-315.

Lutovac, S., \& Kaasila, R. (2011). Beginning a pre-service teacher's mathematical identity work through narrative rehabilitation and bibliotherapy. Teaching in Higher Education, 16(2), 225-236.

Lutovac, S., \& Kaasila, R. (2014). Pre-service teachers' future-oriented mathematical identity work. Educational Studies in Mathematics, 85(1), 129-142.

Lutovac, S., \& Kaasila, R. (2018). Future directions in research on mathematics-related teacher identity. International Journal of Science and Mathematics Education, 16(4), 759-776.

Ma, J. Y., \& Singer-Gabella, M. (2011). Learning to teach in the figured world of reform mathematics: Negotiating new models of identity. Journal of Teacher Education, 62(1), 8-22.

McCulloch, A. W., Marshall, P. L., DeCuir-Gunby, J. T., \& Caldwell, T. S. (2013). Math autobiographies: A window into teachers' identities as mathematics learners. School Science and Mathematics, 113(8), 380-389.

Mosvold, R., \& Bjuland, R. (2016). Positioning in identifying narratives of/about pre-service mathematics teachers in field practice. Teaching and Teacher Education, 58, 90-98.

Neumayer-Depiper, J. (2013). Teacher identity work in mathematics teacher education. For the Learning of Mathematics, 33(1), 9-15.

Nichols, S. L., Schutz, P. A., Rogers, K., \& Bilica, K. (2017). Early career teachers' emotion and emerging teacher identities. Teachers and Teaching, 23(4), 406-421.

Noblit, G. W., \& Hare, R. D. (1988). Meta-ethnography: synthesizing qualitative studies. Newbury Park: Sage.

Oslund, J. A. (2016). After the elementary mathematics teacher workshop: Stories of becoming complex instruction teachers. The Elementary School Journal, 116(3), 437-458.

Owens, K. (2008). Identity as a mathematical thinker. Mathematics Teacher Education and Development, 9, 36-50.

Owens, K. (2014). The impact of a teacher education culture-based project on identity as a mathematically thinking teacher. AsiaPacific Journal of Teacher Education, 42(2), 186-207.

Palmér, H. (2016). Professional primary school teacher identity development: a pursuit in line with an unexpressed image. Teacher Development, 20(5), 682-700.

Pausigere, P., \& Graven, M. (2013). Unveiling the South African official primary mathematics teacher pedagogic identity. Perspectives in Education (Special Issue: Primary Mathematics: Addressing the Crisis), 31(3), 19-33.

Pipere, A., \& Mičule, I. (2014). Mathematical identity for a sustainable future: An interpretative phenomenological analysis. Journal of Teacher Education for Sustainability, 16(1), 5-31.

Polkinghorne, D. E. (1995). Narrative configuration in qualitative analysis. In J. Hatch \& R. Wisniewski (Eds.), Life history and narrative (pp. 5-23). London: Falmer.
Ricoeur, P. (1991). Narrative identity. Philosophy Today, 35(1), 73-81.

Rodgers, C., \& Scott, K. (2008). The development of the personal self and professional identity in learning to teach. In M. CochranSmith, S. Feiman-Nemser, D. J. McIntyre \& K. E. Demers (Eds.), Handbook of research on teacher education: Enduring questions and changing contexts (pp. 732-755). New York: Routledge.

Sandelowski, M., Docherty, S., \& Emden, C. (1997). Focus on qualitative methods. Qualitative Metasynthesis: Issues and techniques. Research in Nursing and Health, 20, 365-371.

Sfard, A., \& Prusak, A. (2005). Telling identities: In search of an analytic tool for investigating learning as a culturally shaped activity. Educational Researcher, 34(4), 14-22.

Skog, K., \& Andersson, A. (2015). Exploring positioning as an analytical tool for understanding becoming mathematics teachers' identities. Mathematics Education Research Journal, 27(1), 65-82.

Skott, J., van Zoest, L., \& Gellert, U. (2013). Theoretical frameworks in research on and with mathematics teachers. ZDM Mathematics Education, 45(4), 501-505.

Spillane, J. P. (2000). A fifth-grade teacher's reconstruction of mathematics and literacy teaching: Exploring interactions among identity, learning, and subject matter. Elementary School Journal, 100(4), 307-330.

Spitler, E. (2012). From resistance to advocacy for math literacy: One teacher's literacy identity transformation. Journal of Adolescent and Adult Literacy, 55(4), 306-315.

van Putten, S., Stols, G., \& Howie, S. (2014). Do prospective mathematics teachers teach who they say they are? Journal of Mathematics Teacher Education, 17(4), 369-392.

van Zoest, L. R., \& Bohl, J. V. (2005). Mathematics teacher identity: A framework for understanding secondary school mathematics teachers' learning through practice. Teacher Development, 9(3), 315-345.

Walshaw, M. (2013). Post-structuralism and ethical practical action: Issues of identity and power. Journal for Research in Mathematics Education, 44(1), 100-118.

Wassell, B. A. (2006). The type of teacher I don't want to be: Constructing teacher identity through converse descriptions and student voice. Teacher Education and Practice, 19(2), 149-163.

Wellman, D. (1994). Constituting ethnographic authority: The work process of field research, an ethnographic account. Cultural Studies, 8(3), 569-584.

Wenger, E. (1998). Communities of practice: Learning, meaning, and identity. Cambridge: Cambridge University Press.

Williams, J. (2011). Teachers telling tales: The narrative mediation of professional identity. Research in Mathematics Education, 13(2), 131-142.

Woolhouse, C., \& Cochrane, M. (2015). Educational policy or practice? Traversing the conceptual divide between subject knowledge, pedagogy, and teacher identity in England. European Journal of Teacher Education, 38(1), 87-101. 